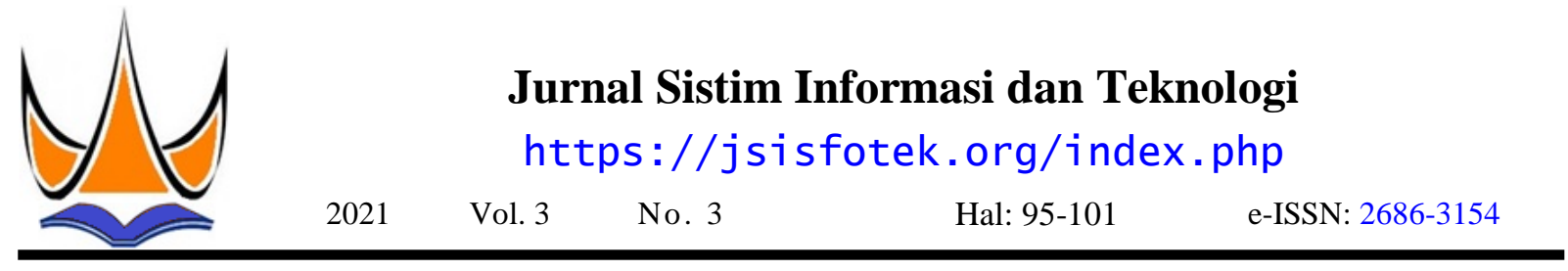

\title{
Klasifikasi Kualitas Mutu Daun Gambir Ladang Rakyat Menggunakan Metode Convolutional Neural Network
}

\author{
Teddy Winanda ${ }^{1 凶}$, Yuhandri Yunus ${ }^{2}$, Hendrick $^{3}$ \\ ${ }^{1,3}$ Politeknik Negeri Padang \\ ${ }^{2}$ Universitas Putra Indonesia YPTK Padang \\ teddywinanda@gmail.com
}

\begin{abstract}
Indonesia is one of the countries which have the best Gambier quality in the world. Those are a few areas in Indonesia which have best gambier quality such as Aceh, Riau, North Sumatera, Bengkulu, South Sumatera and West Sumatra. Kabupaten 50 Kota is one of the regencies in west Sumatra that supplies gambier in Indonesia. The gambier leaf selection is mostly done by manual inspection or conventional method. The leaf color, thickness and structure are the important parameters in selecting gambier leaf quality. Farmers usually classify the quality of gambier leaves into good and bad. Computer Vision can help farmers to classify gambier leaves automatically. To realize this proposed method, gambier leaves are collected to create a dataset for training and testing processes. The gambier image leaves is captured by using DLSR camera at Kabupaten 50 Koto manually. 60 images were collected in this research which separated into 30 images with good and 30 images with bad quality. Furthermore, the gambier leaves image is processed by using digital image processing and coded by using python programming language. Both TensorFlow and Keras were implemented as frameworks in this research. To get a faster processing time, Ubuntu 18.04 Linux is selected as an operating system. Convolutional Neural Network (CNN) is the basis of image classification and object detection. In this research, the miniVGGNet architecture was used to perform the model creation. A quantity of dataset images was increased by applying data augmentation methods. The result of image augmentation for good quality gambier produced 3000 images. The same method was applied to poor quality images, the same results were obtained as many as 3000 images, with a total of 6000 images. The classification of gambier leaves produced by the Convolutional Neural Network method using miniVGGNet architecture obtained an accuracy rate of 0.979 or $98 \%$. This method can be used to classify the quality of Gambier leaves very well.
\end{abstract}

Keywords: Gambier, Convolutional Neural Network (CNN), Image classification, Deep learning, Machine learning.

\begin{abstract}
Abstrak
Indonesia adalah salah satu negara yang memiliki kualitas gambir terbaik di dunia. Beberapa daerah di Indonesia yang memiliki kualitas gambir terbaik seperti Aceh, Riau, Sumatera Utara, Bengkulu, Sumatera Selatan, dan Sumatera Barat. Kabupaten 50 Kota adalah salah satu daerah di Sumatera Barat sebagai pemasok gambir dunia. Pemilihan daun gambir dilakukan secara konvensional oleh petani dengan melihat langsung warna, bentuk dan ketebalan daun. Petani biasanya mengelompokkan kualitas daun gambir menjadi bagus dan jelek. Computer Vision dapat membantu petani untuk melakukan klasifikasi daun gambir secara otomatis. Untuk membuat system ini secara otomatis dengan computer vision, maka dibutuhkan citra daun gambir untuk membentuk dataset. Dataset ini yang kemudian digunakan untuk proses training dan testing klasifikasi daun gambir. Citra sudah dikumpulkan dalam penelitian ini sebanyak 60 citra daun gambir yang bersumber dari ladang rakyat Kabupaten 50 Kota. 60 citra daun gambir itu terdiri dari 30 citra gambir kualitas baik dan 30 citra gambir kualitas jelek. Selanjutnya citra daun gambir diolah menggunakan pengolahan citra digital menggunakan bahasa pemrograman python dengan framework TensorFlow dan Keras. Untuk mendapatkan waktu proses yang lebih cepat, digunakanlah sistem operasi Linux Ubuntu 18.04. Metode yang digunakan untuk mendapatkan klasifikasi kualitas daun gambir ini adalah Convolutional Neural Network (CNN) dengan arsitektur miniVGGNet. Hasil gambar augmentasi untuk gambir kualitas bagus sebanyak 3000 gambar. Sedangkan untuk gambar kualitas jelek juga didapatkan hasil yang sama sebanyak 3000 gambar, dengan total gambar menjadi 6000 gambar. Klasifikasi daun gambir yang dihasilkan dengan metode Convolutional Neural Network menggunakan arsitekur miniVGGNet mendapatkan tingkat akurasi 0,9987 atau 99,87\%. Metode ini dapat digunakan untuk mengklasifikasikan kualitas daun gambir dengan sangat baik.
\end{abstract}

Kata kunci: Gambir, Convolutional Neural Network (CNN), Image classification, Deep learning, Machine learning.

(C) 2021 JSisfotek

\section{Pendahuluan}

Gambir (Uncaria Gambier Roxb) adalah satu produk dalam komoditi pertanian yang diekspor keluar negeri. Indonesia merupakan negara yang $80 \%$ mengisi kebutuhan ekspor dunia. Kebutuhan ekspor dunia itu dipenuhi dari beberapa wilayah seperti Sumatera Barat, Riau, Sumatera Utara, Bengkulu, Sumatera Selatan, dan Aceh. Di wilayah Sumatera barat, gambir umumnya banyak ditemui di Kabupaten 50 kota. 
Kabupaten 50 kota memasok 50\% dari kebutahan dataset [11]. Metode CNN berhasil mendeteksi 10 jenis nasional gambir untuk kualitas ekspor [1].

Dengan tingginya tingkat permintaan pasar akan gambir, bidang ilmu pertanian memiliki peran yang sangat penting untuk meningkat kualitas gambir yang bagus. Akan tetapi, kualitas gambir yang bagus saat ditanam ataupun dipanen tidak cukup untuk mendapatkan indikator bahwa kualitas ekspor sudah bagus. Daun gambir yang bagus atau yang kualitas eksport adalah hasil sortir secara konvensional yang dilakukan oleh pentani. Petani mampu menentukan kualitas daun gambir dengan cepat dikeranakan pengalaman yang telah dilalui selama bertahun-tahun. Dengan kondisi seperti itu maka tingkat kesalahan manusia sangat besar didalam menentukan kualitas daun gambir yang hanya bergantung pada penglihatan petani.

Ilmu yang berhubungan erat dengan penentuan kualitas produk, jenis dan kuantitas secara visual, bidang ilmunya adalah computer vision [6]. Computer Vision umumnya membahas tentang klasifikasi objek dan deteksi objek pada gambar [3]. Computer Vision yang digunakan umumnya terdari dari pengumpulan gambar, pre-processing, training dan deploy [4]. Setelah semua proses tersebut dilalui maka akan dihasilkan model yang akan digunakan untuk klasifikasi atau deteksi gambar yang baru [5]. Pembuatan model didalam computer vision biasanya didasari pada metode Convolutional Neural Network (CNN) [2].

CNN merupakan metode yang dapat memproses data dua dimensi. CNN dibuat melalui proses pengembangan dari Multi Layer Perceptron [7]. CNN memiliki jaringan yang dalam dan tergolong kepada Deep Neural Network dan banyak digunakan dalam memproses data citra [8].

Pada penelitian yang pernah dilakukan sebelumnya, metode CNN digabungkan dengan Ensemble learning digunakan untuk melakukan pengenalan objek pada gambar dengan menggunakan dataset cifar-10. Dataset cifar-10 memiliki spesifikasi yang dibentuk dari 60.000 citra berwarna, dikelompokkan dalam 10 kategori, dan diatur pixel pada ukuran 32×32. Tingkat keberhasilan yang dihasilkan oleh metode yang diajukan diatas adalah $98,89 \%$ [9].

Penelitian lain yang dengan metode CNN ini adalah penelitian yang bertujuan untuk menentukan penyakit pada jagung. Penyakit jagung itu dikelompokkan 2.1. Pembuatan Datase kepada Coomon Rust, Gray Leaf, dan Northern Leaf Mengumpulkan data dilakukan untuk dapat Blight [10]. Pemodelan untuk pengenalan penyakit memperoleh informasi data-data yang dibutuhkan jagung ini menggunakan metoda CNN. Tingkat dalam rangka mencapai tujuan penelitian. Pada keberhasilan model untuk mengelompokkan penyakit penelitian ini peneliti melakukan observasi langsung di jagung di penelitian ini adalah $99 \%$.

Tidak hanya untuk melakukan pendeteksian penyakit Kecamatan Kapur IX Kabupaten 50 Kota, Propinsi Sumatera Barat. Gambar 2 mempelihatkan tanaman pada jagung, metoda CNN juga digunakan untuk mendeteksi penyakit pada tanaman padi dengan menggunakan sebanyak 500 gambar untuk membentuk

Akurasi yang tinggi merupakan hasil yang banyak didapatkan oleh peneliti yang menggunakan metode CNN. Seperti penelitian tentang struktur daun yang memakai 44 jenis daun. Data jenis daun yang digunakan adalah data dari MK Leaf Dataset. Model CNN yang digunakan dalam penelitian ini adalah CNN standar, GoogleNet, dan AlexNet. Akurasi yang didapatkan oleh ketiga model ini adalah 99\%, 100\%, dan $96 \%$ [13].

Didasari dari masalah yang ditemui dalam penentuan kualitas daun gambir dan beberapa penelitian yang berkaian dengan deteksi gambar, maka penulis mengusulkan metode CNN untuk melakukan klasifikasi daun gambir. Oleh karena belum didapati dataset daun gambir, maka penulis secara langsung melakukan pengambilan gambar daun gambir di perkebunan. Untuk menyeragamkan kualitas gambar, kamera DLSR digunakan untuk melakukan pengambilan gambar. Arsitektur CNN yang diterapkan pada penelitian ini adalah miniVGGNet.

\section{Metodologi Penelitian}

Garis besar tahapan kegiatan yang dilakukan dalam penelitian dijelaskan dalam kerangka penelitian yang ada di Gambar 1.

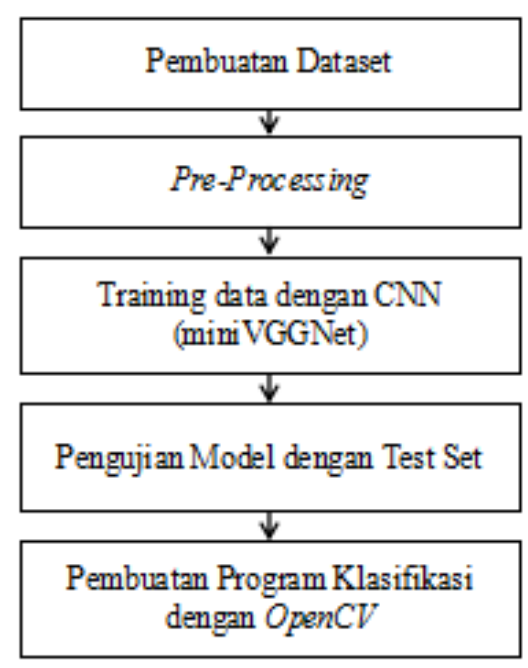

Gambar 1. Kerangka Penelitian gambir secara utuh.

Jurnal Sistim Informasi dan Teknologi Vol. 3 No. 3 (2021) 102-107 


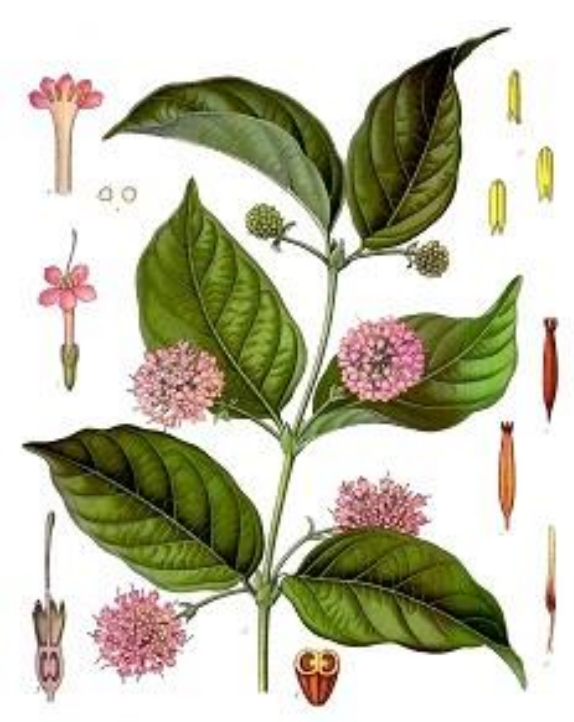

Gambar 2. Tanaman Gambir

\subsection{Pre-Processing}

Bagian ini merupakan salah satu bagian yang cukup signifikan dalam proses training. Pre-processing berfungsi untuk pengolahan awal gambar daun gambir. Hal yang dilakukan ditahap ini adalah menyeragamkan besar gambar gambir yang telah dikumpulkan. Untuk menghasilkan model dengan akurasi yang baik salah satunya dipengaruhi oleh jumlah dataset yang digunakan. Oleh karena itu dilakukan teknik augmentasi gambar untuk meningkatkan jumlah dataset. Selain itu dataset yang telah dihasilkan akan dikelompokkan menjadi Traindataset (trainset) dan Testdataset (testset). Traindataset adalah gambar yang digunakan untuk proses training. Sedangkan Testdataset digunakan untuk proses pengujian awal. Biasanya komposisi trainset $(70 \%)$ dan testset $(30 \%)$ dari total keseluruhan dataset.

\subsection{Training data dengan CNN (miniVGGNet)}

Arsitektur CNN yang digunakan untuk pembuatan model ini adalah mini VGGNet. Parameter yang digunakan untuk pembuatan model ini seperti pada Tabel 1. Parameter-parameter ini yang selanjutnya akan diterjemahkan kedalam program dengan menggunakan library Tensorflow. Proses training mini VGGNet diperlihatkan di Gambar 3.

\begin{tabular}{|c|c|c|c|c|}
\hline Layer Type & Output Size & $\begin{array}{l}\text { Filter } \\
\text { Stride }\end{array}$ & Size & I \\
\hline $\begin{array}{l}\text { INPUT } \\
\text { IMAGE }\end{array}$ & $32 \times 32 \times 3$ & & & \\
\hline CONV & $\begin{array}{l}32 \times 32 \times \\
32\end{array}$ & $3 \times 3, \mathrm{~K}$ & $=32$ & \\
\hline Layer Type & Output Size & $\begin{array}{l}\text { Filter } \\
\text { Stride }\end{array}$ & Size & I \\
\hline ACT & $\begin{array}{l}32 \times 32 \times \\
32\end{array}$ & & & \\
\hline $\mathrm{BN}$ & $\begin{array}{l}32 \times 32 \times x \\
32\end{array}$ & & & \\
\hline $\mathrm{CONV}$ & $\begin{array}{l}32 \times 32 \times x \\
32\end{array}$ & $3 \times 3, K$ & $=32$ & \\
\hline Layer Type & Output Size & $\begin{array}{l}\text { Filter } \\
\text { Stride }\end{array}$ & Size & I \\
\hline ACT & $\begin{array}{l}32 \times 32 \times \\
32\end{array}$ & & & \\
\hline $\mathrm{BN}$ & $\begin{array}{l}32 \times 32 \times \\
32\end{array}$ & & & \\
\hline POOL & $\begin{array}{l}16 \times 16 \times x \\
32\end{array}$ & $2 \times 2$ & & \\
\hline DROPOUT & $\begin{array}{l}16 \times 16 \times \\
32\end{array}$ & & & \\
\hline CONV & $\begin{array}{l}16 \times 16 \times \\
64\end{array}$ & $3 \times 3, K$ & $=64$ & \\
\hline ACT & $\begin{array}{l}16 \times 16 \times x \\
64\end{array}$ & & & \\
\hline $\mathrm{BN}$ & $\begin{array}{l}16 \times 16 \times \\
64\end{array}$ & & & \\
\hline CONV & $\begin{array}{l}16 \times 16 \times \\
64\end{array}$ & $3 \times 3, K$ & $=64$ & \\
\hline ACT & $\begin{array}{l}16 \times 16 \times \\
64\end{array}$ & & & \\
\hline $\mathrm{BN}$ & $\begin{array}{l}16 \times 16 \times x \\
64\end{array}$ & & & \\
\hline POOL & $8 \times 8 \times 64$ & $2 \times 2$ & & \\
\hline DROPOUT & $8 \times 8 \times 64$ & & & \\
\hline $\mathrm{FC}$ & 512 & & & \\
\hline $\mathrm{ACT}$ & 512 & & & \\
\hline $\mathrm{BN}$ & 512 & & & \\
\hline DROPOUT & 512 & & & \\
\hline $\mathrm{FC}$ & 10 & & & \\
\hline SOFTMAX & 10 & & & \\
\hline
\end{tabular}




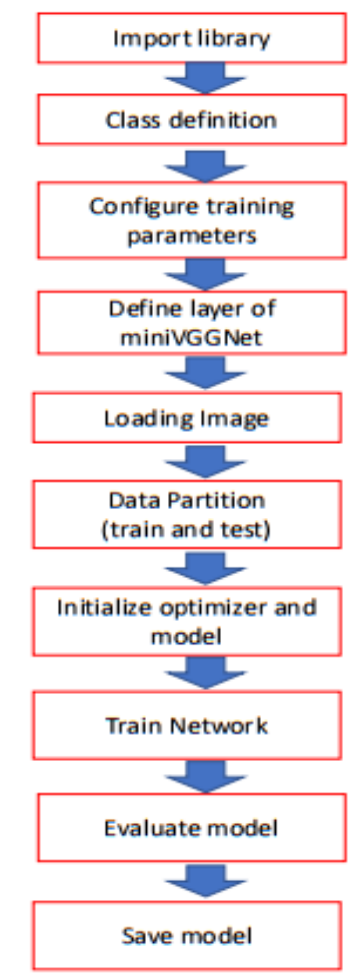

Gambar 3. Algoritma Program

\subsection{Pengujian Model dengan Test Set}

Gambar tahapan ini dilakukan untuk menguji model yang sudah dihasilkan oleh proses training dengan testset yang sudah disiapkan pada tahapan sebelumnya. Proses ini juga akan menilai tingkat keakurasian model dalam melakukan klasifikasi kualitas daun gambir.

\subsection{Pembuatan Program Klasifikasi dengan OpenCV}

Tahapan ini merupakan proses deploy model kedalam program yang sesungguhnya yang diharapkan program akan bekerja secara langsung atau realtime classification system. Penulis membuat program aplikasi yang mampu untuk mengklasifikasikan daun gambir melalui gambar dari webcam dan gambar yang dipilih. Sistem yang dirancang menggunakan software phyton 3.8 dengan library Tensorflow dan Keras. Implementasi ini dilakukan untuk membandingkan hasil yang didapatkan dengan analisa secara manual dan dengan sistem. Dalam membangun sebuah sistem yang berbasis komputerisasi ada 2 komponen yang harus dipenuhi, yaitu spesifikasi hardware dan software. Tabel 2 memperlihatkan spesifikasi hardware yang digunakan. Tabel 3 merupakan software pendukung yang digunakan untuk melakukan penelitian ini.

Tabel 2.Tabel Hardware Pendukung

\begin{tabular}{ll}
\hline Product & Spesifikasi \\
\hline Laptop & MSI GF63 Thin 9RCX \\
Processor & Intel Core i7-9750H \\
Memory & 8GB \\
Hard disc & 250GB \\
\hline
\end{tabular}

Tabel 3. Tabel Software Pendukung

\begin{tabular}{ll}
\hline Product & Spesifikasi \\
\hline Sistem Operasi & Linux Ubuntu 18.04 64 bit \\
Processor & Intel Core i7-9750H \\
Memory & $8 \mathrm{~GB}$ \\
Hard disc & $250 \mathrm{~GB}$ \\
\hline
\end{tabular}

\section{Hasil dan Pembahasan}

\subsection{Gambar Daun Gambir}

Gambar 4 dan Gambar 5 adalah contoh gambar daun gambir dengan kategori bagus dan jelek. Dari dua ketegori gambar daun gambir ini, data yang dimiliki adalah 30 gambar untuk masing-masing katergori. Jadi total data gambar daun gambir yang digunakan dalam penelitian ini adalah 60 buah gambar daun gambir. Untuk mendapatkan dataset penilitian yang lebih banyak dan bervariasi, maka dilakukanlah proses augmentasi data gambar daun gambir ini. Proses augmentasi data tidak menghilangkan informasi asli yang dimiliki oleh gambar gambir yang didapatkan dengan memfoto daun gambir tersebut.

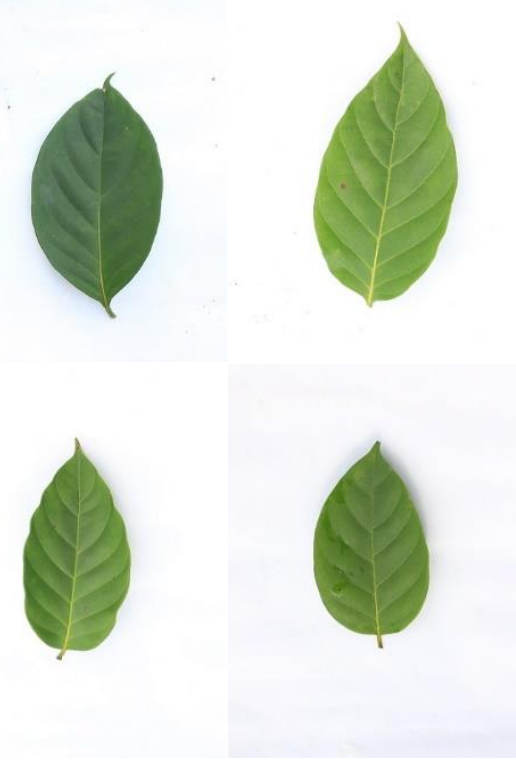

Gambar 4. Daun Gambir Kualitas Bagus 


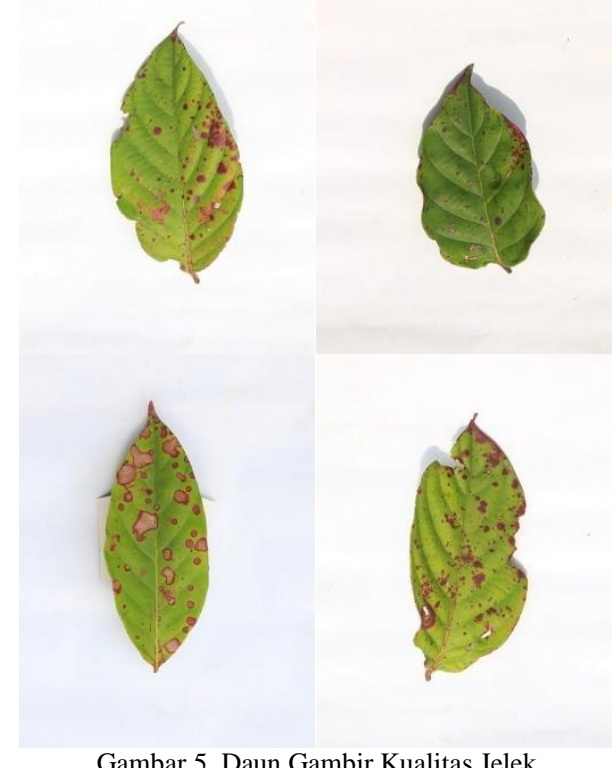

Gambar 5. Daun Gambir Kualitas Jelek

\subsection{Data Augmentasi}

\subsection{Hasil Training miniVGGNet}

Cara proses training yang dilakukan dalam pembuatan Proses ini bertujuan untuk memperbesar jumlah gambar model memanfaatkan GPU yang ada di laptop untuk hingga dataset yang dihasilkan memiliki jumlah mempercepat proses. Gambar 10 memperlihatkan gambar yang cukup untuk melakukan training. Proses proses training yang dilakukan di Ubuntu 18.04. Kotak augmentasi diperlihatkan seperti di gambar 6. Proses merah memperlihatkan bahwa CUDA sudah berhasil augmentasi terdiri dari beberapa tahapan seperti dijalankan dalam proses training model gambir. labelling dan resize, pre-processing, augmentasi dan Gambar 11 memperlihatkan bahwa proses training hasil sebagai image dataset. Setelah proses augmentasi, sudah selesai dilakukan saat epoch mencapai 100 . total gambar untuk membentuk dataset adalah 6000 Kotak merah memperlihatkan hasil akhir training gambar. Tampilan proses augmentasi di terminal dimana didapatkan hasil akurasi model 0.9987 atau seperti di gambar 7 .

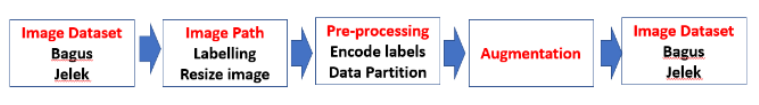

Gambar 6. Algoritma Program

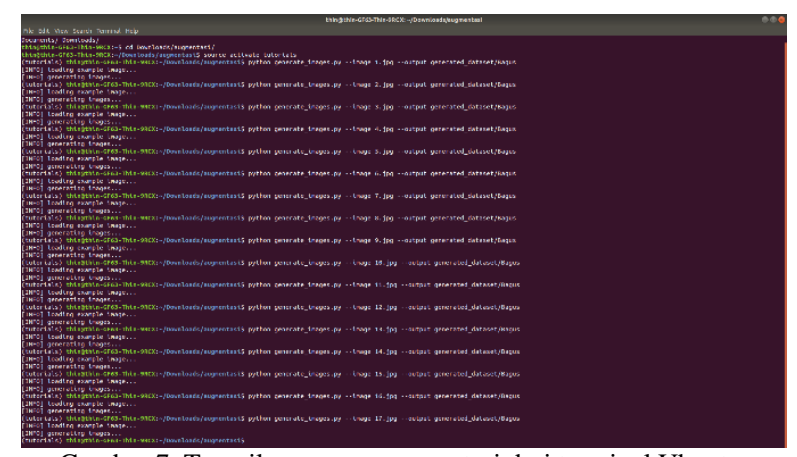

Gambar 7. Tampilan proses augmentasi dari terminal Ubuntu.

Gambar 8 dan gambar 9 memperlihatkan contoh data gambar hasil augmentasi dari kategori daun gambir bagus dan kategori daun gambir jelek. sekitar $99,87 \%$.

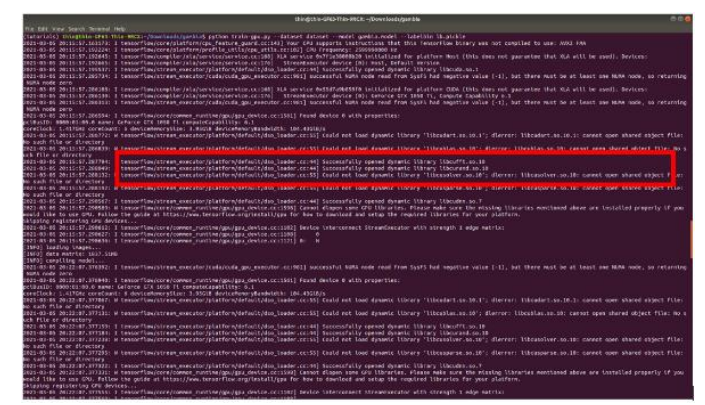

Gambar 10. Tampilan proses training dari terminal Ubuntu

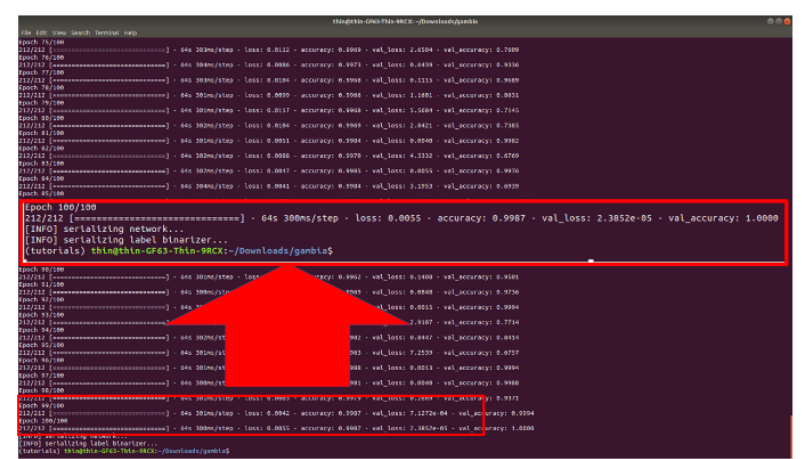

Gambar 11. Akhir proses training miniVGGNet 


\subsection{Klasifikasi Daun Gambir}

Setelah dilakukan pembuatan model, tahap selanjutnya adalah tahap pengujian dengan gambar yang baru. Proses ini dilakukan dengan tujuan untuk menguji model dengan sumber gambar selain gambar dataset. Gambar 12 memperlihatkan beberapa hasil pengujian klasifikasi daun gambir dengan kualitas bagus. Gambar 13memperlihatkan beberapa hasil pengujian klasifikasi daun gambir dengan kualitas jelek.

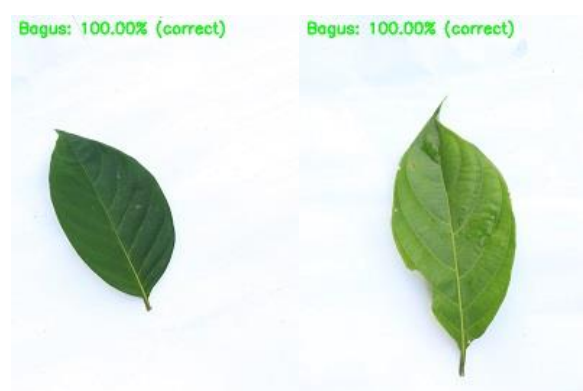

Gambar 12. Hasil klasifikasi daun gambir kualitas bagus

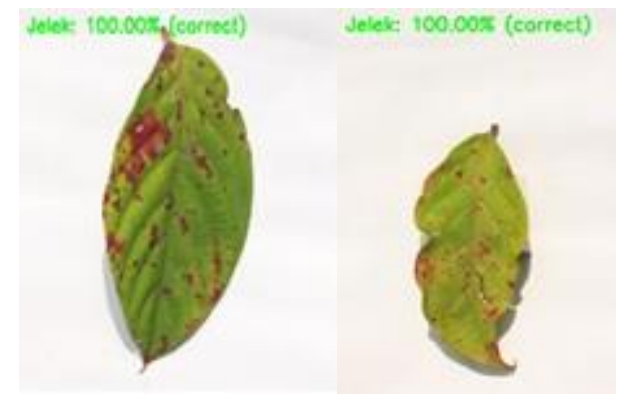

Gambar 13. Hasil klasifikasi daun gambir kualitas jelek

Dari Gambar 12 dan 13 tersebut terlihat bahwa uji coba terhadap model yang dihasilkan dari proses training, dapat mengklasifikasikan gambar daun gambir dengan benar.

\section{Kesimpulan}

Setelah melalui serangkain proses dalam pembuatan model klasifikasi, model kualitas daun gambir berhasil diciptakan. Proses augmentasi berhasil melipatgandakan jumlah gambar sebanyak 100 kali dari setiap gambar asli. Hasil gambar augmentasi untuk gambir kualitas baik sebanyak 3000 gambar. Sedangkan untuk gambar kualitas jelek juga didapatkan hasil yang sama melalui proses serupa. Total gambar menjadi 6000 gambar. Dengan menggunakan CNN dengan arsitektur miniVGGNet dihasilkan nilai accuracy sebesar 0,9987 atau 99,87\%. Untuk pengembangan penelitian akan ditambahkan jenis gambar kualitas sedang. Selain itu akan direncanakan pembuatan mekanik berupa beltconveyor sehingga sistem dapat digunakan sebagai sistem klasifikasi daun gambir yang utuh.

\section{Daftar Rujukan}

[1] Ismail, E. H., (2019). Indonesia Negara Utama Produsen dan Eksportir Gambir Dunia. Republika. [Online] (Updated 22 Augustus 2019). Available at: Accessed 10 December 2021].

[2] Danukusumo, K. P., Pranowo., \& Maslim, M. (2017). Indonesia Ancient Temple Classification Using Convolutional Neural Network. International Conference on Control, Electronics, Renewable Energy and Communications (ICCREC). DOI: http://dx.doi.org/10.1109/iccerec.2017.8226709 .

[3] Effendi, M., Fitriyah, F., \& Effendi, U. (2017). Identifikasi Jenis dan Mutu Teh Menggunakan Pengolahan Citra Digital dengan Metode Jaringan Syaraf Tiruan. Jurnal Teknotan, 11(2). DOI: https://doi.org/10.24198/jt.vol11n2.7 .

[4] Liu, L., Ouyang, W., Wang, X., Fieguth, P., Chen, J., Liu, X., \& Pietikäinen, M. (2019). Deep Learning for Generic Object Detection: A Survey. International Journal of Computer Vision, 128(2), 261-318. DOI: https://doi.org/10.1007/s11263-01901247-4.

[5] Santoso, A., \& Ariyanto, G. (2018). Implementasi Deep Learning Berbasis Keras Untuk Pengenalan Wajah. Emitor: Jurnal Teknik Elektro, 18(1), 15-21. DOI: https://doi.org/10.23917/emitor.v18i01.6235.

[6] Du, J. (2018). Understanding of Object Detection Based on CNN Family and YOLO. Journal of Physics: Conference Series, 1004. DOI: https://doi.org/10.1088/1742-6596/1004/1/012029 .

[7] Dewa, C. K., Fadhilah, A. L., \& Afiahayati, A. (2018). Convolutional Neural Networks for Handwritten Javanese Character Recognition. IJCCS (Indonesian Journal of Computing and Cybernetics $\quad$ Systems), 12(1). DOI: https://doi.org/10.22146/ijccs.31144 .

[8] Putra, W. S. E. (2016). Klasifikasi Citra Menggunakan Convolutional Neural Network (CNN) pada Caltech 101. Jurnal Teknik ITS, 5(1). https://doi.org/10.12962/j23373539.v5i1.15696 .

[9] Mo, W., Luo, X., Zhong, Y., \& Jiang, W. (2019). Image Recognition Using Convolutional Neural Network Combined with Ensemble Learning Algorithm. Journal of Physics: Conference Series, 1237(2). DOI: https://doi.org/10.1088/17426596/1237/2/022026.

[10]Hidayat, A., Darusalam, U., \& Irmawati, I. (2019). Detection of Disease on Corn Plants Using Convolutional Neural Network Methods. Jurnal Ilmu Komputer dan Informasi, 12(1). DOI: https://doi.org/10.21609/jiki.v12i1.695 .

[11]Lu, Y., Yi, S., Zeng, N., Liu, Y., \& Zhang, Y. (2017). Identification of Rice Diseases Using Deep Convolutional Neural Networks. Neurocomputing, 267, 378-384. DOI: https://doi.org/10.1016/j.neucom.2017.06.023 .

12]Zhang, S., Huang, W., \& Zhang, C. (2019). Three-Channel Convolutional Neural Networks For Vegetable Leaf Disease Recognition. Cognitive Systems Research, 53, 31-41. DOI: https://doi.org/10.1016/j.cogsys.2018.04.006 .

[13] Sabri, N., Aziz, Z. A., Ibrahim, Z., Rasydan, M. A., \& Hafiz, A. (2018). Comparing Convolution Neural Network Models for Leaf Recognition. International Journal of Engineering \& Technology, 7(3.15), 141 . DOI: https://doi.org/10.14419/ijet.v7i3.15.17518 